IDEAS \& OPINION

\title{
THE MYSTERy KNOWN As DEPRESSION
}

\author{
Arthur Janov* \\ The Primal Center, Santa Monica and Claremont Graduate University, USA
}

\begin{abstract}
This opinion article presents the result of years of observation of depressive patients. It is a report on their treatment while undergoing a feeling therapy that deals with reliving past imprinted trauma in context of new research in neurology and biology. The underlying premise is that early traumatic events, including the time in the womb and at birth, leave an imprint aided by epigenetic methylation that endures and comes to dominate our lives. It later accounts for serious ailments and the imprint plays a role in our behavior, interests and attitudes. Through a feeling psychotherapy that allows patients to relive their traumatic history might be possible to found a way to make profound changes in depression.
\end{abstract}

Key words: Repression; Imprint; Methylation; Defenses; Gestation and birth trauma

\section{INTRODUCTION}

Depression has been considered a mysterious 'monster,' even in professional circles where it is still deemed an enigmatic illness.

The condition has proven so resistant to treatment that one therapeutic approach, based on cognitive-behavioral principles, calls itself "Taming the BEAST," an anagram for "treatment modules" in Biology, Emotions, Activity, Situations and Thoughts. (Gilson \& Freeman, 1999) Today, however, the most common treatment strategy is also the simplest. It involves the use of antidepressants, now the third most widely prescribed type of drug in the country, often administered by general practitioners untrained in psychology. (Mojtabai \& Olfson, 2011) When neither drugs nor therapy are effective, some psychiatrists resort to that holdover from horror movies, electro-shock therapy, which is gaining renewed acceptance under a different moniker, electroconvulsive therapy (ECT).

Until recently, ECT was considered the last resort in the battle against the beast; it was used when psychiatrists concluded that the only option left was to blast the patient's brain with electrical energy. Now, psychiatrists have gone beyond applying shocks from outside the skull and have opted for an even more radical alternative - brain surgery. (Mayberg et al., 2005) To say the least, it is a most drastic attempt at a solution. The procedure - known as deep brain stimulation (DBS) - involves drilling four holes in the brain with screws inserted into the skull. Surgeons then plant electrodes near the center of the brain in a region called Area 25, part of the subcallosal cingulate gyrus which has been identified as a having a key

*Correspondence to: Arthur Janov, e-mail: Primalctr@mac.com

Received July 6, 2013; accepted August 20, 2013; Act Nerv Super (Praha) 55(3), 79-107. 
role in major depression. Activated by a pacemaker in the chest, the devices emit a steady stream of electric pulses to stimulate the area, thereby easing the otherwise entrenched symptoms.

Suppose, however, that we could access deep brain centers without any physical or chemical intervention and make alterations in the circuit - perhaps even rewire it - in a natural way. I submit that Primal Therapy does just that. It is possible to found a natural, non-invasive way to access the same deep brain structures that are affected by surgery and/or tranquilizers. And my opinion is that it is possible to successfully treat many deep depressions, and measure results through brainwaves and biochemistry. (For a detailed discussion, please see my book, Why You Get Sick and How You Get Well: The Healing Power of Feelings. [Janov, 1996]) By finding this psychotherapeutic avenue to the affected brain areas, we can avoid many misdirected approaches, especially the risky use of surgery and heavy drugs. Certainly, natural feeling methods are to be chosen over a serious brain surgery.

It is not that depression is refractory to psychotherapy. It is that psychotherapy is refractory to depression. In its current state, psychotherapy in many of its approaches is too superficial to change anything profoundly. It isn't that depression cannot be touched by therapy because it is such a serious and unfathomable affliction; it is that conventional therapy is not designed to probe the depths of the unconscious where generating sources lie. And today it seems that the only way conventional therapists can get to those deep-lying imprints is through surgery or jolts of electricity. (The crucial concept of the imprint and its corollary, resonance, the gateway to deep brain levels, is explored in detail below.)

The reason we, as a profession, have had to resort to such drastic and dangerous measures is because most treatments thus far have addressed the neocortex; actually, the front left tip of the neo-cortex, the prefrontal area. Since clinical approaches such as talk therapy and behavior modification concentrate on the cognitive part of the brain, they may neglect the source and the site of the real problem. The success of the surgery itself, with some 80 percent of patients reporting their depression lifted, should tell psychotherapists that the site of the problem may lie deeper. The most serious cases are rightly referred to as "deep" depressions because the problem often emanates from the antipodes of the brain. To be clear, my opinion is that a psychotherapy for depression that fails to probe the depths of the brain, the depths of the unconscious, cannot be successful. The generating source remains untouched.

Diagnosis in psychotherapy too often is a matter of nomenclature, one that may not accord with neurology and the body that houses it. Conventional diagnosis is often symptom-based, focused on external signs - labored movements, lack of interest, and a bewildering array of other symptoms detailed below - while ignoring root causes. I propose a diagnosis, however, that encompasses the system as a whole - neurobiology, behavior and psychology as an ensemble, an integrated view.

Some leaders in the field acknowledge that psychology as a profession is in need of a radical overhaul. The debate about the confounding state of psychotherapy seems to escalate with every new edition of the Diagnostic and Statistical Manual of Mental Disorders (D.S.M.), considered the bible of mental illness and treatment. This year, on the eve of the publication of the D.S.M.-5, the first revision in almost 20 years, the calls for a whole new way of thinking in psychology seem more urgent than ever. On both sides of the Atlantic, there have been recent calls for a complete paradigm shift in the way we understand and treat mental illness.

In a prepared statement on the eve of the D.S.M.-5's release, the British Psychological Association stated it was unhelpful to see mental health issues as illnesses with biological causes. "On the contrary, there is now overwhelming evidence that people break down as a result of a complex mix of social and psychological circumstances - bereavement and loss, poverty and discrimination, trauma and abuse," stated Dr. Lucy Johnstone, a clinical psychologist who helped draft the association's provocative statement. (Doward, 2013) Meanwhile in the U.S., Dr. Thomas Insel, director of the National Institute of Mental Health, based near Washington, D.C., states that there can be no progress in the field so long as we continue to use the D.S.M. as our guidebook. He claims it leaves out the complexities of 
neuroscience, biology and genetics. The manual is even counterproductive, he argues, because it is used to deny funding to researchers looking for the real causes behind afflictions such as psychosis and depression, simply because their research proposals cut across the D.S.M.'s outdated categories. "Dr. Insel is one of a growing number of scientists who think that the field needs an entirely new paradigm for understanding mental disorders," concludes a recent New York Times article about the controversial manual, "though neither he nor anyone else knows exactly what it will look like." (Belluck \& Carey, 2013)

According to my view the last part of that statement is fully true, the paradigm already exists. I am not a lone voice in the wilderness, but my opinion based on my experience and four decades of work is that for example "Primal Therapy", that was in focus of my work and experience is one of them that offers precisely the new paradigm that is needed in modern psychology. But as with all new revolutionary theories in science, the status quo is slow to recognize fundamental changes in any field, and loathe to adopt them. (See the article by Agustin Gurza on Primal Therapy and scientific revolutions, originally published in the Journal of Primal Therapy (Gurza, 1976) and more recently posted online as an appendix to my book, "Grand Delusions." (Gurza, 2005) What this paper seeks to address is precisely that paradigm shift, probing for causes and generating sources that have been neglected in our work. I agree that we need to reorient our field and provide a new understanding of mental illness, which I take as my task. What I am proposing is a total paradigm shift not only in our view of this affliction but also its treatment. We need to reframe our thinking about it, and recognize that what is missing is the "why?" We need to ask: What is depression, and where does it come from? Why is the patient depressed?

Since I first published The Primal Scream: The Cure for Neurosis in 1970, the subtitle became the lightening rod for criticism because we used the term "cure." Nobody dares speak of curing mental illness. Yet the issue seems to be a double-bind. We utilize therapies that cannot cure, and then look askance at those who claim to have found one. "Cure" is not an opprobrious term. What is opprobrious is that we have given up on proper therapy and made it an unacceptable word. "Cure" is not a term to be avoided in the interest of pure science; it is a state to be sought after assiduously. We owe it to the millions who suffer from depression with no real hope of finding their way out of the darkness.

Depression has been a mystery for a long time because we have ignored the connection between a patient's current mental and physical health and long-ago imprinted traumas experienced in childhood but also in the womb and at birth. That left us with a narrow range of choices: either drug the patient or operate on him. Preferably, we need to help him plunge deep into that unconscious. We need to help the patient find the nexus between his current state of depression and its deep-lying sources. Only the patient can make that connection inside himself; our task is to help him gain access to those deeper levels of brain function.

History will provide us with the answer; history is the cause and history is the savior.

\section{DEPRESSION AND THE PRIMAL PARADIGM}

Let me begin by proffering my definition of depression, and how it is understood within the paradigm of Primal Therapy. One caveat before proceeding: Our understanding of depression arises from an observational, not statistical, perspective. Ours is basically an empirical science; wanting to know rather than knowing what we want. What I describe has been seen in hundreds of our patients over 45 years. It is a new paradigm, a departure from the conventional notions of depression. If we try to understand it within the old frame of reference we will fail. Depression has its roots in the earliest moments of a patient's life, during gestation and birth. Since first espousing these theories more than four decades ago, advancements in brain research have offered mounting evidence to support our theory about the role of early trauma in causing mental illness. What is still difficult to accept by some is our assertion that reliving those traumatic experiences, including birth, is the way to reverse 
depression. In this sense, exploring the mind has been a little like exploring the world to prove it is round; it often can't be believed until somebody actually makes the journey. In the development of our therapy, we have made no a priori assumptions in our observations. From the beginning, we have always let ourselves be guided by one unassailable truth - the experience of our patients.

Not long ago, a group of my depressive patients met to discuss their problems and the overwhelming pain that surrounds them. As they talked it became apparent that there were numerous things they had in common. Looking back at the experience of their lives, they identified certain symptoms and tendencies in their feelings and behavior, including:

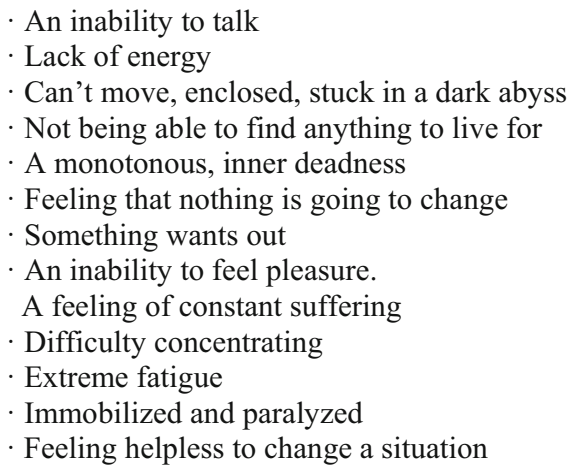

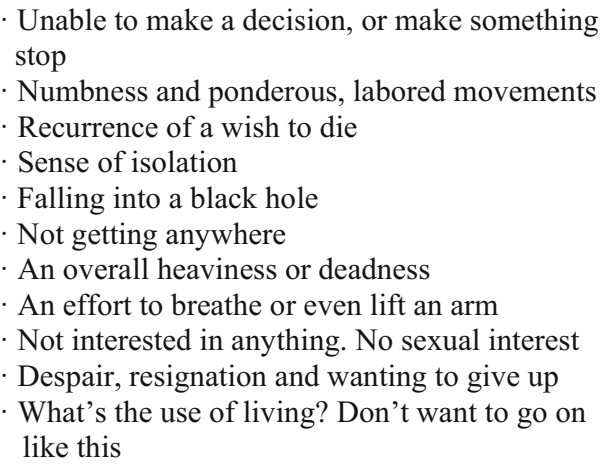

This group of "symptoms" is based on my experience with my depressives describing their own general condition. But in addition, what these patients have come to realize, however, is that they were describing the sensations of a birth trauma, the common denominator of their communal experience. No one suggested this in any way because we would not have known what to suggest.

If we were to overlay a transparency illustrating the characteristics of depression over one showing the effects of the birth trauma, we would find that they match perfectly. Everything a person felt during the birth trauma back then is reflected in the description of her current depression. Clear examples are contained in the list of depressive symptoms enumerated by my group of patients; they are expressing exactly what they felt as infants being born. The traumas set down in the womb, at birth and during infancy are coded, registered and stored in the nervous system. They become a template for what happens later.

\section{THE THREE LEVELS OF CONSCIOUSNESS}

To understand how it is possible to trace the causes of a lifelong illness - and its cure - to the very beginning of a person's life, I must explain my view of the three levels of consciousness.

We basically have three brains in one as MacLean $(1985,1990)$ already proposed in 1960s: the brainstem, the limbic system, and the neocortex, each representing different stages of evolution, from shark, chimp to human brain, respectively. These neurologic stages of brain growth correspond to three distinct levels of consciousness: the earliest, pre-verbal stage of infancy, followed by childhood and finally present-day awareness. At each level of brain development, we have specific needs that must be fulfilled uniquely. The earlier the needs the more lasting the consequences when they are not fulfilled, and the more grave the imprint. In infancy, we have a need to be touched and nurtured tenderly. On the second line, we seek fulfillment of emotional needs: to be listened to, to feel secure and supported, to get an empathetic response to our hurts and fears. And the third level involves intellectual stimulation, communication and understanding by the parents. Fulfillment on this level can lead to clear and logical thinking; to an accuracy of perceptions. 


\subsection{First Line - The Brainstem}

The first level, the brainstem, is a primitive or reptilian brain, which is our oldest brain system (MacLean, 1990). The brainstem was the first to evolve, and the first part of the central nervous system to develop in human evolution. It seems that we never lost that part. We just added new brain tissue on top of it. The brainstem deals with instincts, basic needs, survival functions, sleep, and basic processes that keep us alive such as body temperature, blood pressure, heart rate and very deep breathing. At this level, we can store a carrying mother's depression, anxiety, stress, drug-taking, smoking, or drinking. Mother can also communicate, through her changing hormones, her unconscious rejection of her coming baby, which then becomes stored in the baby's brainstem. Such experience is not stored as ideas, obviously, since we don't yet have a neocortex, the thinking, intellectual, comprehending mind. But what is important is that the imprints in this storehouse will later motivate certain thoughts and aberrations of thinking. The brainstem imprints the deepest levels of pain because it is developed during gestation and handles life-and-death matters before we see the light of day.

\subsection{Second Line: The Limbic/Feeling System}

The second level of consciousness is basically the limbic system of the brain (and its affiliates), which is responsible for feelings and their memory (MacLean, 1990). It provides images and artistic output, processes certain aspects of sexuality, and is partly responsible for anger and fear. The limbic system possesses some key structures which affect brain function. They are the hypothalamus and thalamus; the hippocampus, which is the guardian of emotional memory; and the amygdala.

The hippocampus contains the archives of early experience, particularly trauma, and also puts a damper on amygdala activation so that our reactions themselves do not become a danger; after all, continually high blood pressure and heart rate will threaten our existence. The hippocampus has a high density of stress hormone receptors and is therefore quite sensitive to stress. The context of a feeling is predominantly organized by the hippocampus. It gives us an anchor for our feelings - a time and place-and allows us to connect to our feelings.

The amygdala is one of the most ancient structures of the brain and the oldest structure of the limbic system. It is the hub of the emotional system; the gateway to feelings. It gives us the sensation behind feeling, while the later developing hippocampus registers those feelings as facts. Early traumatic memory is consolidated by the amygdala. Luckily, when the going gets rough, it can help manufacture its own opium to hold back pain. In this way it helps us remain unconscious. It is truly a wonder that this small brain structure "knows" when to stop pain and can release a poppy derivative to help. More, it tells other brain structures about how much to release and when to stop.

The hypothalamus works with the lower structure, the pituitary, to govern the release of key hormones, not the least of which are the stress hormones. When we have strong emotions, it is the hypothalamus that organizes our response. (Within the hypothalamus lie two different kinds of nervous systems, the sympathetic and parasympathetic, which are key to understanding depression and are discussed in detail below.)

The thalamus is the central switchboard of the brain, relaying certain aspects of feeling to the frontal cortex. It can decide a feeling is too powerful to be felt and orders that the message not be relayed, and thus kept from awareness. The thalamus talks straight neurochemical talk, a language that expresses itself wordlessly. Yet it can translate painful messages into something understandable by the frontal cortex. If the pain is too much, the message that 
arrives is garbled. If it is acceptable, the gates open and the message is clearly understood we know what we feel.

\subsection{The Third Line: The Neocortex}

The third line is the neocortex, the part of our brain that was the last to evolve and the one responsible for intellectual functioning, generating ideas and thinking (MacLean, 1990). The left pre-frontal area deals with the external world, helps us repress and, when able, to integrate feelings. It comes online at about the third year of life. The frontal cortex is part of the feeling system to the degree that it gives meaning and understanding to our physiologicemotional reactions. The neocortex serves as a portal for entry into the suffering component of memory, a portal that cannot operate by itself. It's the first door we walk through toward retracing our history and understanding our pain.

We can be fulfilled or deprived on any of these levels; when deprivation occurs so does pain, as the lack of fulfillment means that the integrity of the system is threatened. And pain is most often accompanied by its counterpart, repression. Fulfillment is more serious and urgent as we descend down the neuraxis on what I call the chain-of-pain. Indeed our biology dictates that deep pain elicits strong repression, to keep the pain at manageable levels. Heavy repression on the first line can mean a deadness of affect, a lack of good interconnection to bodily function so that sex is problematic and appetite is dulled; there is a lack of energy and passion. Symptoms on the first line include ulcers, colitis, and breathing problems. Symptoms on higher levels have different manifestations; the inability to make a decision, to be independent and forthright and to be aggressive.

This is simply a brief overview of the three levels in order to better understand the origins of depression and its therapy. If we consider that those ancient brains are still active in our head, the nature of the problem becomes clearer. All three brains should work in harmony throughout our lives. How they all get along is paramount. We need clear channels among the levels; otherwise there is distortion. Early trauma, however, creates a lifelong disharmony and disconnection among brain levels, resulting in many forms of mental illness. Essentially, neurosis is driven by lower brain centers that are trying to communicate to higher ones but are unable because a disconnection has occurred, a disconnection caused by the imprint of an early lack of love that spells hopelessness and helplessness. The goal of therapy is to restore that harmony, neurologically and psychologically, because consciousness (not to be confused with awareness) means all three levels working fluidly.

\section{WHAT IS DEPRESSION?}

Throughout the ages, writers and thinkers have come up with poetic sobriquets to describe depression. Hippocrates called it the "black bile." Susan Sontag famously dubbed it "melancholy minus its charms." For Flaubert, it was simply "the eternal 'what's the use?' " And in his book The Noonday Demon, Andrew Solomon says "depression is grief out of proportion to circumstance." (Solomon, 2002) Today, this ancient malady is poised to become the second leading cause of disability through the remainder of this decade, according to a report from the World Health Organization titled "The Global Burden of Disease." (World Health Organization, 2004) By any name, depression has clearly become a plague among us. From a public health standpoint alone, it behooves us to understand precisely what it is and how to treat it humanely.

People often say they "feel" depressed, but depression is not a feeling. It is a defense against feeling,- against an accumulation of imprinted pain. As such, it is a protective device to keep us unconscious, or rather, to keep the unconscious from becoming conscious. It holds down, via its handmaiden repression, all of the catastrophic feelings and sensations from 
womb-life, infancy and childhood that, if unleashed from their safe, subconscious stronghold, would threaten the integrity of our conscious awareness. It is the ultimate survival strategy.

Depression is a system-wide state of repression that blankets many feelings. It is the history of the body's traumatic experience exerting its force. And ultimately, it is the state of repression elevated to a higher level. For this reason, the depressive is chronically awash in suffering because he/she cannot feel those specific, early feelings. The organism seems to say, "Better to feel numb than feel what lies below and go crazy." Thus, the labored movements, feeling flat and unemotional, the lack of energy, and so on; all the feelings adumbrated by my patients at the beginning of my discussion. Any expression - anger, for example - can temporarily ease depression because it lifts repression a bit. But depression is certainly not, as Freud believed, anger turned inward. (Freud, 2005)

A normal person is rarely depressed; he has no backlog of feelings lying unresolved inside. He is open to feel and does not repress unpleasantness. He will be sad when it is appropriate. But sadness is a "now" event, a real feeling related to real situations. Depression is a "then" feeling, unrelated to now. If the young child could feel each and every original imprint, he would not be depressed in his life. The depressive, on the other hand, is stuck in time. He is stuck back in his past whether he is conscious of it or not, so that everything he does is a symbolic portrayal of that past. This means that we are all open to sadness when our defenses give way. To suddenly be out of work, left alone or excluded by one's friends is most distressing, but depression is quite another matter. We should feel distressed, despairing, unhappy, sad; these are normal reactions. Not so with depression, which has as its kernel a deep hopelessness and helplessness. This is a basic imprint from long ago that can be triggered when one of those adversities occur. This imprint is often set down either during gestation or at birth when there was no escape from the traumatic input, such as a massive dose of anesthetics given to the mother during delivery which, as we shall see, effectively shuts down the baby as well. It is often this hopelessness that is triggered when seemingly not-so-serious events happen and depression occurs.

Feeling down and discouraged in response to losing a job, or breaking up with a mate, or after the death of a loved one, is different from a chronic, interminable depression. The former may be what is commonly known as "grieving" or "bereavement" which lasts for some weeks or a few months. The person has a normal response: gloominess, sadness, crying, feeling terrible, which stops after a time. What happens is that the person is reacting with real feelings. "Sad," for example, is a feeling; depression is not. Depression happens when you don't feel the real feelings. Those feelings agitate the deep brain levels and activate the imprint. The depressive feels all that; the imprint on the move toward conscious/awareness. It never makes it, however, as repression intercedes. But a deep despair and resignation set in, and a feeling of defeat and wanting to give up; and above all, that gloom and doom that is the hallmark of so many depressions. That is the original, precise, imprinted feeling that is trying to push its way into consciousness; it colors and dominates the present. We see the depths of the imprint in a syndrome known as endogenous depression, something that appears without apparent warning, leaving us helplessly deep into its maw. It has been labeled endogenous because until now we did not know where it came from or why. It is so deep that it seems to come from nowhere, but that nowhere/somewhere is deep in the brain.

When external defenses fail or are under attack, what the depressive experiences is the repression, not the feelings themselves. He feels the pressure against those feelings pushing down into his system. That pressure produces effortful speech and movement and total exhaustion so that the depressive has little energy and moves about in slow motion; "my feet are stuck in cement," as one patient put it. In short he feels the weight of the repression, the ineffable force of keeping feelings down. He does not feel the feelings themselves. Once he does, the depression can begin to lift.

In depression there is the feeling of "heaviness," a lack of energy, which can be so great that even getting out of bed seems like a monumental chore. It makes everything a Herculean 
job, so that normal tasks such as talking or raising one's arm can become a great effort, even chewing on solid food. There is little or no energy left for enjoyment, pleasure, sexual drive, or any drive, for that matter, other than the wish to find a way to end the suffering.

So the depressive goes to a therapist for help; he/she usually has to be coaxed into it. What he/she gets is encouragement and hope that the therapist will make it all better someone who will perform magic. He/she wants to be "pulled out" of her state; a symbolic feeling that was there when the original event - birth trauma - was taking place. Someone literally pulling his/her out, breathing life into him/her. The patient's passivity requires an active, assertive therapist. The therapist becomes his/ her "friend" because he/she has rarely ventured out to make friends. And he/she will willingly take orders and obey his directions. But he/she has to offer hope and encouragement to combat that loss of hope deep down.

Give a depressive a new outlet - a new job, a party or a chance to go shopping - and all of the inner-directed pressure now pours out in manic activity. He will literally "throw himself" into his work. He will be "happy" for those moments when his work will make him happy. What has really happened is that he has found an outlet to release the primal force. Here we see the basis for bipolar or manic-depression. Not a different disease but a different kind of template - hopeless depths followed by manic energy. When repression fails, manic activity sets in. The imprint reflects the same cyclic event that occurred at birth. The person was stuck in what I call the trough and was blocked, then with great effort made it out. The template down and then up - is played out in the cycle of giving up and trying manically to finish. It is the same energy source but a different way of handling it. So we can see that some of us shut down early in life and, lacking outlets, we become "dead," globally and emotionally shut down. Others shut down and "act" alive. If being the "happy clown" pleases one's parents, then the act will continue. Among the professional comedians I have treated this was never truer. I am treating a depressive now whose mother was chronically ill; he became funny to try to cheer her up. Though it never worked for long, it became a habitual pattern. His need? A happy mother who could love him. Take away the chances to please and the lurking sadness will begin to ascend. If one was disliked, suppressed, and rejected at every turn, then deadness and depression will be reinforced. How we develop depends on later life circumstance: Were the parents loving? Were they not tyrannical? Could they allow free expression? If there were free expression and lots of touch, then the imprint will be kept at bay because it was not compounded, but it will never go away until relived and connected.

\section{THE KEY ROLE OF EPIGENETICS}

Although genetics may be partly responsible for depression in rare cases, by and large it is early life experience (including experience in the womb and birth trauma), that is the root cause. What we see at work is epigenetics, the altering of gene function without changes in the underlying DNA sequence (Booij et al., 2013). Those alterations, or deviations, if you will, often involve a biochemical process known as methylation. And it is through methylation that psychological trauma is imprinted. Thus the trauma - which can be as simple as a lack of caring and love by the mother - becomes "fixed" in the system and endures. It is the imprint, the linchpin of depression. The biochemistry, and ultimately the brain have been rerouted, sealing in depressive tendencies. It is this imprint that ultimately must be addressed and resolved.

What the scientific evidence shows more and more is that gestation and birth events are critical for later disease. In a 2010 study conducted at the Hannover Medical School in Germany, researchers concluded that "epigenetics is of considerable interest for the understanding of early life stress in depression." The study, published in the journal Current Opinion in Psychiatry, found, among many other things, that unloved and untouched children had a predisposition to depression. (Schroeder, Krebs, Bleich, \& Frieling, 2010). Recent work 
by a team of Canadian researchers also pointed to the critical role played by epigenetics. (Booij et al., 2013) The following passage is from their article:

\begin{abstract}
"The functioning of the hypothalamic-pituitary-adrenal (HPA) axis and serotonergic (5-HT) system are known to be intertwined with mood. Alterations in these systems are often associated with depression. However, neither (is) sufficient to cause depression in and of themselves. It is now becoming increasingly clear that the environment plays a crucial role, particularly, the perinatal environment. In this review, we posit that early environmental stress triggers a series of epigenetic mechanisms that adapt the genome and program the HPA axis and 5-HT system for survival in a harsh environment. We focus on DNA methylation as it is the most stable epigenetic mark. Given that DNA methylation patterns are in large part set within the perinatal period, longterm gene expression programming by DNA methylation is especially vulnerable to environmental insults during this period. We discuss specific examples of genes in the 5-HT system (serotonin transporter) and HPA axis (glucocorticoid receptor and arginine vasopressin enhancer) whose DNA methylation state is associated with early life experience and may potentially lead to depression vulnerability. We conclude with a discussion on the relevance of studying epigenetic mechanisms in peripheral tissue as a proxy for those occurring in the human brain and suggest avenues for future research."
\end{abstract}

It seems that the fastest changes in methylation occur early in our lives, at the very least in the neonatal period, though this thesis is subject to further study. What is important now is that certain genes which should not be silenced, are. Thus, certain means of expression are suppressed, which is often the case in depression. None of this means that methylation "causes" the affliction but rather, there are adverse events very early in life that increase its production.

Though the Canadian researchers emphasize the perinatal period, we have found the imprint to lie earlier, as well. If the neonate is especially sensitive to environment insults, it surely is possible that those insults can occur earlier and form the primordial imprint that later gives rise to depression. Methylation, in brief, offers the primordial event that sets the prototype for later inhibition and repression; thus, high methylation may be a predictor for later depression. It means that certain key genes which should find expression are silenced, especially due to modification of the genes promoter region. The tendencies for no or difficult expression are imprinted.

My opinion is that some of these changes in physiology occur during our life in the womb, when the set-points of so many hormones are being established, including thyroid hormone. Indeed if we give a small does of thyroid medication to depressive patients there is a transient improvement. One may think that such deficiencies are genetic but there are events that can cause them that are not always obvious. They are only obvious when the patient in therapy descends down to the far reaches of the unconscious where the crucial explanation of one's depression lies. One again relives the birth experience, the suffocation, strangulation, the hopeless battle to get out - the unutterable and ineffable despair. Of course, it is not given a name until years later but the feeling is there engraved in the nervous system. We can feel hopeless without giving it a label. In the face of adult adversity, the old imprint - wanting to give up - appears and is now called depression.

We give it that name because we have not seen the generating sources of deep imprinted despair, something we have observed many times. We name it depression because we do not know the hopelessness inside that makes us miserable. We give depression the name of the defense instead of its cause - pain. 


\section{THE NATURE OF THE IMPRINT}

It seems that new research provides critical evidence on epigenetics, and how imprints through methylation can be passed down from one generation to another (Booij et al., 2013). A key could be repressed memory that endures and persists throughout our lives; it drives behavior, symptoms and aggravated depression. It turns out that imprints can be passed down from parents to baby and from grandparents to baby. Some genes which should be turned on are not, while those that should be off remain on. Critical in this process is methylation, which is a chemical reaction where a methyl group is transferred from a donor molecule (S-adenosylmethyonine) to the cytosine on DNA or a histone. The reaction is catalyzed by DNA methlytransferase (DNMT). A certain amount of methylation occurs naturally but trauma, such as maternal neglect in infancy, can cause excess methylation of key genes involved with the stress response. (Weaver et al, 2004) Methylation depends on the work of the chemical methyl group which is recruited when there is a traumatic event, and helps embed that memory. It seems that when there is a surge of methylation, part of it, the element 621-13, attaches or adheres to the gene. It is now part of the DNA and turns on or off certain hormones and other neuro-chemical processes. Once that happens and methyl is recruited, the genetic unfolding is thereafter altered.

In short, methylation can be an agent of (transcription) repression, or more exactly, a marker for it. In this context, repression is a systemic event that involves the whole body. If you reverse the methylation chemically (perhaps with new drugs they are developing), one can still have repression. But remove the repression through therapy and you may see demethylation. Until the studies are done, it's unclear how closely the two are linked, and in what tissues. A study at Duke University showed that when female mice were fed a diet rich in methyl it completed altered the fur pigment of the offspring. (Dolinoy, 2008) In other words, it acted like a genetic inheritance when it was not. It was the result of experience which is the linchpin of our theory--epigenetics.

In this context, traumatic events in very early childhood, (and I assume, including the period of gestation), leave a mark or tag on a gene that affects us possibly for life. They found that even grandparents affected the imprints of the grandchildren, which we will get to in a moment. But suffice to say that the experiences of our forebearers can endure and be passed down the genetic chain, the inheritance of acquired characteristics. This is something science thought impossible decades ago.

It is what we all know; that early love makes us stronger and less anxious. But it turns out that if the rat mothers were licked and groomed early on in their lives, that experience could be passed on to their offspring. The genes could be modified by the methyl group (and also other chemicals) in a beneficent way. In humans, that implies a good history in the mother means a good childhood for the children. And more loving by the mother, the less methylation in the child. And with less chronic stress hormone production there may be less chance of serious diseases later on, such as Alzheimer Disease.

To make sure that these changes in the rat pups resulted from experience and not hereditary, they let normally stable rat pups be raised by neurotic negligent mothers. And the result was still the same, unstressed babies. These babies had mothers who had normal amounts of methyl in their systems. Thus rats raised by loving mothers could pass it onto offspring even when the adopted mother was not loving. The genes for stress hormone output had minimal methylation. In other words love was passed down the genetic chain. So normal babies raised by negligent and inattentive mothers still had low methyl levels in their hippocampus. The babies started life one leg up, a good start in life despite a bad childhood. I believe that changes in the genes, methylation and acetylation, must occur very early as the whole neuronal system is evolving. So before we can state what causes depression or anxiety, we need to observe the early epigenetics at work. Again, pups born to unloving mothers were handed over to loving mothers, and those born to bad mothers reared by loving mothers still seemed to be normal and relatively unmethylated. Let us remember that methyl 
exists throughout the system but it is not the general amount of it but rather how much is found in specific genes (Weaver et al, 2004).

Another reason this research is important: they found that unloving mothers of rodents causes methylation of the estrogen receptors in female offspring. Then when they had offspring of their own the offspring were deficient in estrogen which made them less attentive and loving to their own babies. We as yet do not know how many key chemical processes can be affected by lack of early love. And more, we have no idea how many hormones are changed in neurotic mothers (heavily methylated) and how that affects myriad adult behaviors. Is depression inherited? There may be precursors for it which is never manifested if there were plenty of love later in childhood. Is some of the tendency to methylation inherited or epigenetically passed on? And does that form the basis for depression? It seems from the research just cited that that neurotic mothers (methylated), are ineluctably forced to be unloving, thus laying the groundwork for depression in the offspring later on (Weaver et al, 2004).

And what other hormones are depleted by this scenario? Are we born with a tendency to anxiety? Possibly, but then the imprint is not methyl so much as acetyl, in this case. With acetylation there are more faults in the repressive system. Acetylation (recruiting acetyl) pretty much produces the opposite of methylation, a tendency to open rather than close, toward expression rather than repression. The role of acetylation is inexact for now and requires further exploration.

Taken together these data suggest that trauma produced heavy methylation in those children who grew up in orphanages. And that process then affected much more in terms of brain and neuronal development. So when we find a mother who is not loving we need to know that she may being driven by her epigenes; she is a victim of those changes. Her cortisol/stress hormone level militates against maternal instincts. Methylation shuts down a number of "natural" behaviors. In neurosis we cannot be natural and appreciate nature because we are disconnected and alienated from our own nature, from our biography, history and feelings. We cannot rely on our feelings to guide us because they have effectively been shut down. Literally, the feelings are aliens. We have found in most patients but pronounced in depression, that patients on the verge of these feelings in sessions often run a fever. The body treats the feelings as a menace, a danger and something to be avoided; yet it is also what can liberate us.

Can we reverse or undo methylation? The research informs us that with rats who had been damaged, and raised by unloving mothers, when they were infused with trichostatin they did not show evident damage. As though the trauma never occurred. This drug removes methyl from the system. This is not exactly the same as demethylation. However, it did undo history (Weaver et al, 2004). This is what I think may be happening during the reliving and focusing on the imprint. There might be a change in methylation so as to reverse history; this is what we shall study in our future research projects. It seems to me the natural way provides far less possibility for collateral damage to the system. Since we already have found that chronically high cortisol levels have been reversed in our therapy, it would perhaps follow that methylation could also be reversed. In a way, the levels of methylation can be a marker for having been loved early on or not having been loved. We could tell more than the statements by the person who claims he was loved in his childhood if he were indeed not loved. How much denial is there?

Neurochemistry may be better relied on because biochemistry has no reason to lie and is not motivated by denial. It can be a marker for post traumatic stress. The more abuse as a child in these cases the more methylation produced. When we add this to our future research on telomeres and cortisol we will begin to have precise measures of the pain in us. And we will know when a drug is too dangerous for us, particularly the drugs like marijuana that tend to open us to ourselves; to our feelings and pain. Finally we will have a marker for the efficacy of certain psychotherapies. Does the therapy undo the past? Does it help relieve 
repression and therefore depression? Is there great first line pain in anxiety states? What seems to be the case is that love obviates methylation and produces normal beings.

K. J. S. Anand and associates state that in a number of suicides by violent means "the significant risk factors were those perinatal events that were likely to cause pain in the newborn." (Anand \& Scalzo, 2000) (More on the link between suicide and perinatal trauma below.) They also point out the carrying mothers who smoke heavily had babies more prone to criminality later on. And mothers who took drugs while pregnant had children far more prone to drug use, both serious opiates (morphine) and speed (amphetamine).

There are literally hundreds of studies now to bolster the hypothesis about early imprints, how they last and alter our systems. Some twenty years ago, most of this research had not been thought of. (Again, this is discussed in detail in Primal Healing. (Janov, 2006) In another revealing study carried out in Canada in 1998, David P. Laplante and Michael L. Meaney of Montreal's McGill University looked at women who were pregnant during a severe ice-storm to assess the long-term effects of stress on their offspring. (Laplante, et al., 2004) The researchers write: "We suspect that high levels of prenatal stress exposure particularly in early in pregnancy, may negatively affect the brain development of the fetus... Imprinting at birth may predispose individuals to certain patterns of behavior that remain masked throughout most of adult life."

\section{THE IMPORTANCE OF TELOMERES}

Elizabeth Blackburn and Elissa Apel in Nature (11 Oct. 2012). (Blackburn \& Epel, 2012) reported on a number of studies of telomeres: in 2004 a study compared white blood cells of mothers with chronically ill children with those mothers with healthy children. Mothers of ill children had shorter telomeres. It is likely that stress is a factor. And that means increased cortisol levels with possible shorter telomeres. It is not short term stress that is the culprit but enduring stress; what could be more enduring than the imprint?

What cortisol may do, inter alia, is increase the enzymatic action of telomerase which affects the function of telomeres. To be clear: what that enzyme may do is get busy fighting deterioration taking place with the input of primal pain. This, it seems, increased telomerase happens to prevent further neuro-biologic damage to the system. A research team led by Owen Wolkowitz of the University of California, San Francisco, has been studying telomeres and depression. (Wolkowitz, Reus, \& Mellon, 2011) What telomerase does ordinarily is help maintain the length of the telomeres, even lengthen them. They are protective. And they go up when depressives take antidepressants; they also go up in animals where it is associated with increased nerve cells in the hippocampus. It appears that the hippocampus deals with the facts of feeling and the memory of it. It is seriously affected by depression. The longer the depression the shorter the telomeres, and it becomes a life-or-death matter. They have found, for example, the very serious pancreatic cancer, is associated with shorter telomeres in blood cells. These people were also studied before the onset of cancer so we cannot say that telomeres shortened because of the onset of cancer. Telomeres maintain the stability of genes; it may be that unstable individuals equal unstable telomeres. There are other cancers associated with shorter telomeres, as well. (There is a book soon to be published by Ed Park, M.D on telomeres). Imprinted pain has a lot to do with depression and with later serious illness. We will study this among our patient population.

Telomeres are shorter in chronic depressives, and that fact is crucial. Why? We can to assume that there is an imprint of early trauma to set up the depression, in the first place. That means pain. There may be a great amount of imprinted pain in depressives. This seems to be also true with immune disorders, as depression affects the immune system adversely. Chronic depressives have shorter telomeres. That can mean imminent serious illness and early death. I believe that a feeling therapy that attacks the imprint is life-saving. We are beginning to see why. One problem we have is that when patients get to earlier brainstem 
imprints the pain is serious; but if they stay with it, it does not last, and makes for great changes throughout the system. I often tell patients, I didn't put the pain there, I am charged with taking it out.

When cortisol is chronically high and telomeres short there is a much greater chance of suffering from certain cancers, including the deadly pancreatic cancer. What causes this cancer? Likely also, early trauma that is imprinted and endures may play a role. Thus a brainstem imprint means a brainstem reaction, and that may mean deep physiological responses, including such afflictions as colitis. Another effect is the appearance of dementia in those with shorter telomeres. Again, we need to look at very early trauma, even in gestation, to find the answer to the questions, what causes cancer? What causes dementia?

When you have a constant pressure and tension on the organs due to the imprint it makes sense that they will give in and break down. The organs are saying, "I can't hold on any more. It is more than I can handle, all too much." It is surprising to me that they do continue to hold their integrity as long as they do.

There is an article in PloS One that underlines the importance of anxiety to damaging the telomeres. It is an important study in which the researchers took blood samples from 5200 women ages 42-69 enrolled in the Women's Health Study. (Okereke, et al. 2012) They analyzed telomere length among them. Those who reported frequent anxiety attacks (phobias) had significantly shorter telomeres. They implied that it would deduct six years from their lives. They conclude that chronic anxiety in childhood leads to premature aging and, of course, a shorter life. Anxiety will kill us; which is why it is so important not to leave the imprint untouched in psychotherapy. Telomeres may soon be the key marker for not only how long we live but how many years a feeling psychotherapy can add to our lives. If we leave it untouched and unchanged the therapy can be a failure.

Stress erodes telomeres very early on, according to late research. So children who spent time in orphanages from birth on had shorter telomeres. I think the evidence is there in so many dimensions; early trauma damages the system in every way possible. We need to pay attention when we carry a baby in the womb and we need to pay real attention to our birth practices which are too often deleterious.

The research emphasizes that the early stress carries on into adulthood. It follows us everywhere and anywhere until we acknowledge it, face it fully, and relive the damage. Paradoxically, as we experience the imprinted damage it goes away, and with it there is a normalizing of many vital signs. Here is supporting evidence for the imprint even if not stated. Why else does it endure and shorten telomeres? Why cannot they make the equation that early trauma stays fixed in the system and drives behavior while shortening our lives? I believe that the earlier the stress, the carrying mother smoking early in pregnancy, the more harmful it will be later on. Lets teach about pregnancy in school so that adolescents understand what pregnancy means for a human life.

\section{THE PHYSIOLOGY OF HOPELESSNESS}

There is an understanding within the psychological profession that pain killers help suppress depression. This means that somewhere there is the recognition that pain may be a factor in causing the disorder. And there is also ample research that points to the fact that some depressions are activated states; stress hormone levels are high, often just as high in anxiety states.

Early alterations in hormones and neurotransmitters are part of the way memory is inscribed. There is a danger: lack of fulfillment. And that danger - of needs not being met - is accompanied by an inordinate secretion of stress hormones. Trauma to the fetus and infant causes the sympathetic system to gear up, producing more adrenaline, dopamine, cortisol, noradrenaline. Once need remains unfulfilled, we are activated...toward fulfillment. When the critical period for fulfillment has passed then these attempts at fulfillment are always 
symbolic. Needing applause, for example, or constant approval. Or, on the flip side, avoiding criticism ("Say I am good. Please. Don't criticize me. I can't take any more.") Once the imprint is embedded by methylation, there is very little that can change it. A person's personality is fixed very early on, and future experience no longer makes a great and radical difference. (It is a study of methylation that we plan for the fall).

Being vigilant is a matter of survival. The whole system is on alert, and stays alert as long as needs are not met and the imprint remains is fixed in the system. It is not that we have a memory and then there are hormone changes; those changes are part of the experience, entwined with the memory. And in turn, it is the changes in biochemistry that influence our ideas and attitudes and behavior.

For instance, feelings affect the hypothalamus, which governs the output of oxytocin and vasopressin, the "love hormones." These hormones help us establish loving relationships, and they also function as partial painkillers. Love can do that. Love is the major painkiller for a young child, so it is not an accident that with early love our "love hormones" are more in abundance. But if no one came to love us early in life when we were lonely or felt neglected, chances are we will suffer from chronically low output of these hormones. The underlying feeling will be "No one wants me," or "No one loves me." It was, and is, hopeless. "No one wants me" governs our life. It is engraved not as an idea but as an ineffable feeling. It makes us shy in social situations, gives us a hangdog look, and compels a defeated posture. All ingredients of depression. In short, depression exists everywhere within us, not just in the brain. It constitutes the subtext we respond to in a therapy. Eventually we will need tranquilizers to hold down the feelings that are pushing from below.

Deficiencies in hormones or neurotransmitters can establish systemic vulnerabilities so that later trauma creates full-blown afflictions. We do not see any apparent disease when the child is five, but the seeds have already been sown. We may say later on, "Anorexia is caused by too much noradrenaline," too little of this or that. However, these are not causes, they are accompaniments to the original trauma, one which we can no longer see and cannot imagine in a person who is 40 years old. The imprint produces deviations in personality and physiology, which ultimately ends in specific symptoms. Thus, the aggressive sympath may have an excess of noradrenaline. It doesn't cause anorexia; it is part of the ensemble of reactions to the original event. Interestingly, Canadian researchers recently reported success in combatting chronic, severe anorexia by using the same deep brain stimulation technique in the same area of the brain that worked to treat depression. (Involved in both cases was Dr. Andres Lozano, a neurosurgeon at the Krembil Neuroscience Centre of Toronto Western Hospital and professor of neurosurgery at the University of Toronto.) The results, originally reported in the medical journal The Lancet, showed that the patients not only gained weight but also saw changes in their mood and their ability to control emotional responses. (Lipsman et al., 2013) "By pinpointing and correcting the precise circuits in the brain associated with the symptoms of some of these conditions, we are finding additional options to treat these illnesses," stated Dr. Lozano. (ScienceDaily 2013)

I do not share the enthusiasm. Indeed, I find this both dangerous - it is experimental brain surgery, after all - and unnecessary. What the researchers claim is that they moderate the activity of dysfunctional brain circuits. So why are those circuits dysfunctional? I submit that it is due to imprints that distort them. In reality, they are not dysfunctional, that have been deviated as a defense against traumatic input. And instead of correcting the deviation of circuits, one must attack the origins of those dysfunctions. Otherwise the vicious cycle in all of psychology and psychiatry continues to repeat; something goes wrong and exudes symptoms, but instead of seeking generating sources one is constantly beating back the symptoms. The surgeons claim they are heralding a new way to treat these illnesses. They claim that they are correcting the precise brain circuits associated with the symptoms. And they are: correcting symptoms and their neural circuits but I submit those circuits are secondary to the imprint. They want to help those who suffer, as we all do, but in attacking the suffering we sometimes forget why that suffering occurs. 
If we don't get to the primal imprint we are left with radical therapies such as brain surgery, which is finding a recrudescence in the field. This approach to anorexia is becoming popular and joining brain surgery for deep depression. These brain surgeons are stimulating the area just below the corpus callosum around the cingulate, which has a lot to do with feelings, whereas we do the same without surgery. Not exactly the same; we connect the imprint so that there is no longer brain activation where it should not be. When patients relive early traumas there is cascade of changes back to normal. It shows us unmistakably how early traumas spread their tentacles throughout the system. If we don't get to the primal trauma, then we have to treat each symptom de novo, and each separately with a different drug or a different psychotherapeutic mode.

We may think of the imprint as a conductor of an orchestra. Since experience affects almost every one of our systems, from the muscles to blood to brain cells, the imprint is bound to cause effects everywhere. The same imprint can, and does, affect the central nervous system, heart, and blood sugar levels. It can alter all of the survival functions because survival was at stake. That means effects on the deep brainstem level where so many survival ploys are organized. Compounding our early pain with later experience makes symptoms manifest, giving rise to high blood pressure, diabetes, migraine headaches, hypothyroidism. The simple fact of chronically high cortisol set up by the imprint can impact memory later in life, not to mention making us more vulnerable to cardiovascular disease.

Let's take a look at some of the physio-chemical effects of an imprint. Suppose there was diminished oxygen at birth and during gestation, which may be caused by a carrying mother who smoked cigarettes during her pregnancy or had anesthesia to kill her pain during labor. These two factors establish a physiologic record in her baby's system. This record orchestrates a large variety of reactions in the baby; each reaction is an adaptation to the original threat against survival. Thus, there is lowered oxygen demands brought about by alterations in breathing, such as shallow and short breaths, then there is lowered thyroid output, lowered blood pressure and body temperature, exhaustion, such as chronic fatigue syndrome; and many phenomena governed by brainstem functions, such as butterflies in the stomach, dizziness, spaciness, and a vague terror. When terror is set down early, the fetus or newborn has no cortical capacity to dilute its impact. The nature of deep terror is so profound that in the reliving decades later it is only possible to feel for moments at a time. And it is dangerous to push a patient deeper into the feeling.

Hopelessness, helplessness, despair, and resignation can be imprinted through this diminished oxygen; all of the true sensations which accompany the memory. These pains elicit its equal and opposite reaction-repression. The pain is "suffocated" in its tracks and the result can be depression, a state that could be compounded by an unfeeling, dictatorial home environment where the child had nowhere to go with her feelings. It is not that parents necessarily suppressed the child's feelings but that they may not have been present emotionally. The result is the same: no one to tell one's feelings to. We are again helpless and hopeless. What is worse, the parasympathetic child makes no effort toward the parent to get love; she gives up and doesn't try.

Research by A. R. Hollenbeck, another specialist in fetal life, documents how any drug given to a carrying mother will alter the neurotransmitter systems of the offspring, especially during the critical period when these neurotransmitter systems are forming in the womb. (Hollenbeck, Grout, Smith, \& Scanlon, 1986) He states that administration of local anesthetics, such as lidocaine (to aid the birth process), during sensitive (critical) periods in gestation is capable of producing enduring changes in the offspring's behavior. Brain chemicals such as serotonin and dopamine can be changed permanently when an animal undergoes birth even with a local anesthetic. This again affects the gating system.

The more painkillers a woman takes during labor the more likely her child will be to abuse drugs or alcohol later on. Karin Nyberg of the University of Gothenburg, Sweden, looked at medication given to the mothers of 69 adult drug users and 33 of their siblings who did not take drugs. Twenty-three percent of the drug abusers were exposed to multiple doses 
of barbiturates or opiates in the hours just before birth. Only three percent of their siblings were exposed to the same levels of drugs in-utero. If the mothers received three or more doses of drugs, their child was five times more likely to abuse drugs later on. (Nyberg, Buka, \& Lipsitt, 2000) Enough animal studies have been done to confirm this finding-that exposure to drugs in the womb changes the individual's propensity for drugs later on.

There is some evidence that a mother taking downers during pregnancy will have an offspring who later will be addicted to amphetamines, known as "uppers" (speed), while a mother taking uppers during pregnancy - coffee, cocaine, caffeinated colas, will produce an offspring later addicted to downers-Quaaludes, for example. And the reason that the person can take inordinate doses, such as drinking two cups of coffee before bedtime and still be able to sleep easily and well, is that there exists a major deficiency of stimulating hormones - the catecholamines. In short, the original set-points for activation or repression have been altered during womb-life and persist for a lifetime.

I have treated patients who have taken enormous doses of speed and have shown very little mania as a result. While other of my patients have taken lethal doses of painkillers in previous suicide attempts, enough to kill anyone else, and still lie awake hours later, only feeling slightly drugged. The severe brain activation by imprinted pain resists any attempts to quell the system.

Psychotherapists must ask the question, "Why does a tranquilizer or painkiller that works on lower centers of the brain calm the patient and change his or her ideas?" We know that it often does. We know that someone suffering an acute heart attack can feel terrible, yet when given a shot of a painkiller, it changes his ideas and attitudes about the experience. This alone should inform us that feelings drive ideas and not vice versa.

\section{DEPRESSION IS REPRESSION ELEVATED TO A HIGHER LEVEL}

"Repression" of pain on various levels can begin in the womb at any point during the nine months of gestation, when the neuroinhibitors in the fetal brain work to quell pain. It is mostly established in the last trimester of pregnancy. At that point, the fetus can feel pain and can repress. The deepest most severe repression occurs during fetal life and at birth because it is nearly always a matter of life and death (Anand \& Scalzo, 2000). These dangerous situations call for extreme responses from the fetus. Repression during this time then becomes global, or system-wide, and affects every aspect of the fetus' body and development. It's easy to sense that kind of early global inhibition in someone because they have a flattened emotionality, having not developed an emotional life before repression set in; and the cause of it happened before they even took their first breath in the world. Incidentally, it can also determine how he functions sexually. He doesn't have the biochemical equipment to be tenacious, aggressive, assertive, optimistic, or future oriented, or sexually erect. This is because the prototype has a global affect on his entire physiological system and the impotence he felt at birth is an impotence that may assert itself in later years sexually. His whole system veers toward less testosterone, dopamine, glutamate, and noradrenaline, lower serotonin and higher cortisol. This is the material of impotence; it is not just an attitude that we can change in order to be more assertive. We are impotent on the deepest levels of brain function.

Evidence is mounting that those with depression are more likely to develop heart disease. (Freedland \& Carney, 2013) Considering that deep depression means deep repression and that means deep pain, the conclusion is not surprising. There are two schools of thought as to why. The first is that the biochemical changes - the release of stress hormones - and autonomic changes occurring during depression affect the heart. The second view is that depression makes people sad and they then neglect their health. I'd opt for the first, only let's go further and say that the very early imprint that makes people depressed also ultimately affects their heart; stress hormones play a role in both conditions. Those who are 
depressed/repressed may have sporadically higher blood pressure in some cases and if one neglects one's medication a heart attack can ensue. This article notes that one in six adults suffer from depression from time to time. Those who have suffered heart attacks and who were also depressed were four times more likely to die of a heart attack in the following six months. Researchers have found that some depressed patients are in a state of hyper-arousal, and that means more pressure and activation of the heart. Stress hormones speed up the heart. What causes chronic high levels of stress hormones? Largely, it is due to the imprints of trauma.

In this context, researchers have implicated that hormones play a significant role in depression. A 1998 report in Scientific American, titled "The Neurobiology of Depression." (Nemeroff, 1998) notes that the monoamine norepinephrine (noradrenaline) is low in depression, some thirty percent less than in a normal population. It leads some professionals to think of depression as a "brain disease." Norepinephrine (a monoamine), by and large, is a stimulating neuronal activator. It is manufactured mainly in circuits that emanate from the locus ceruleus, a brainstem structure. There are projections elsewhere in the brain, particularly, to the limbic system. Because there is not enough of this in depression it may lead to the false conclusion that this deficiency causes depression.

\section{THE BIRTH OF SUICIDE}

The Centers for Disease Control and Prevention recently reported an alarming rise in the number of suicides among middle-aged Americans, especially men in their 50s who suffered a 50 percent increase between 1999 and 2010. (MMWR, 2013) Overall, suicide has now surpassed auto accidents as a cause of death in the United States. In developed countries, it now tops cancer and heart disease as the leading cause of death for people 15 to 49 , according to the recently released report, "Global Burden of Diseases, Injuries, and Risk Factors Study 2010," from researchers at the University of Washington. (IHME, 2010) Worldwide, suicide has come to claim more lives than war, murder and natural disasters combined, as detailed in an alarming Newsweek cover story aptly titled "The Suicide Epidemic." (Dokoupil, 2013) Clearly, suicide has become a major public health concern. Yet, professionals struggle to explain the cause. In a New York Times article about the rising rates, (Parker-Pope, 2013) experts cited multiple possible factors, including the bad economy, increased availability of drugs, and even the unique world view of the Baby Boom generation. The real explanation escapes them because it is hidden in the victims' remote past.

Suicidal depression is not a different disease but rather a breakthrough of feelings through the gating system. It is an agitated sensation where great and intolerable pain surges forth, having broken through the gates. The system does its best to hold it down but to no avail. Then the attitude arises - "the only way to stop the pain is kill myself." The need is not to die but only to end the misery. The more severe the depression, the more likely there are to be thoughts of "what's the use of it all." There is a sense that there are no options and no alternatives, leading to a preoccupation with death and suicide. In the worst case scenario, the denouement of the infant's original drama meant death at the very moment of birth. It meant death then and it means death now through the imprint - that is, the lingering sense of impending doom. The suicide attempt brings the sequence to its logical conclusiondeath. In one way, pain establishes a marker for an unfinished sequence that was originally cut short due to its massive load of pain. Our system keeps returning there to finalize and integrate what could not be integrated early on.

It is difficult, perhaps, to believe that birth problems can give rise to suicidal tendencies years later. This is because we are not used to thinking about physiologic memory. Nor are we used to thinking that the most powerful memories we have are those without words; memories of events which predated our ability to understand what was happening to us. As we have seen, the despair during a birth trauma never goes away. It melds into later behavior 
and exacerbates it. Later in life, adversity provokes hopelessness and despair, a desire to give up, the direct run-off of the birth sequence. "Run-off" is a key concept here because once something in the present resonates with an old memory, we are forced to act out the entire sequence until its logical conclusion. That is why once into the feeling, there is obsessive rumination about death and suicide. The difference is that the newborn can only sense death in a vague way because it has no behavioral options, whereas the suicide case uses death as the behavioral option to end the agony.

Suicide typically involves the run off of the birth sequence in the same way that Pain insinuates itself into sex and carries the sex act out. We saw how, for the parasympath, the birth prototype ended in a near-death experience: death being the only way to end the agony. Being strangled by the umbilical cord or being deprived of oxygen by an overwhelming anesthetic makes the birth struggle agonizing and futile, a sequence with its own irrevocable logic: struggle, suffering, and failure leading toward death. Suicide finishes the evolutionary sequence. The imprinted preoccupation with death occurs in the present while immersed in the past. For those who think about dying as if it were about to happen now - that is, when the current agitation/agony reaches a certain level - it can set off the prototypic feeling. The body is indifferent to the current source of the agitation - the wrenching loss of a spouse. Once the valence of the present trauma is high enough, the old sequence will kick in and then begin its run-off. The result can be death by hanging. Many depressives insist that they could not wake up one more morning in pain. Because they had no idea what was happening or what to do about it, suicide became the logical option. There is rarely a preoccupation with death without resonance occurring, triggering off first-line pain.

Not only does death linger on as a memory in the nervous system, but suicides will often choose a method that reflects the prototype of their birth experiences. So, those strangled on the umbilical cord may hang themselves, or an overdose of pills is chosen by someone who was drugged at birth. Why? Because of the prototype; for a neonate strangling on the cord, further strangling would have ended the agony. Those drowning in amniotic fluid at birth will opt for death by drowning. Case in point: the writer-actor Spalding Gray had a lifetime obsession with drowning. He used to swim in the ocean as far out as he possibly could until the point of exhaustion and then struggled to try and make it back. He killed himself by jumping off the Staten Island Ferry in the middle of the night. I hypothesize that he may have been drowning at birth and the end of the original sequence would be drowning. In other words, I think he died like he was born. This is never to minimize the pain in the present; sometimes it is most devastating and can reach suicidal levels. In Spalding Gray's case, the actor had a terrible auto accident some time before his suicide and I believe that his high level of pain may have set off the original agony. The accident caused a skull fracture and damage to his frontal cortex, which may have further impaired his ability to repress pain. (Williams, 2004) The current trauma is just the trigger; it is the early pain add-on that is often what can push one into a suicide attempt.

Those who received a massive dose of anesthetic at birth may take an overdose of barbiturates, or they might gas themselves in their garage. And so on. I remember one patient who saved up dynamite; having experienced anoxia at birth, he was going to put a stick to his head and blow his head off so that he wouldn't have one second of pain and hopelessness. He laughs at that now, but at the time it spoke volumes of his desperation. Another patient was obsessed with jumping off a building. During her birth by Cesarean, this person had felt wrenched into space with nothing to hang onto. Another patient, battered and squeezed at birth, obsessed about jumping off a bridge head first.

It's not always the case that the suicide method mimics the birth trauma, of course, but it is often what we discover in talking to and observing our patients. If we want to get an idea about our birth, look at our imagined choice of suicide. Conversely, if we want to know the origins of depression, we might examine the birth epoch. Eventually, we will discover the secrets of our beginnings in life. I state this after treating, observing or supervising many hundreds of patients over decades. 
I recently conducted an informal survey in which I asked my patients about their suicide attempts or their fantasies regarding the mode of suicide. Almost without exception the parasympaths chose the passive way out--sleeping pills. They preferred waiting for a slow, sure death. Also, without exception, they were the ones who were drugged at birth. The most drugged, incidentally, would prefer to lie down in the back seat of a car with the motor running and allow themselves to be gassed in death by the exhaust. Another patient, born at home in the freezing winter in Europe where there was little heat, preferred marching out into the snow and letting herself freeze to death. She heard that was the most peaceful way to go. By contrast, the sympaths chose the most active kinds of death: a bullet to the head. One said, "I can't imagine sitting around waiting for death like those who sit in a car." Another sympath said that drowning takes too long and there's too much fright in anticipation: "I prefer jumping in front of a train. It's quick and sure." He was all "smashed up" at birth - total body damage, as he was twisted and turned in order to get out. He knows there was external rotation as he was "presented" in the wrong position and had to be straightened out. Each of two sympaths wanted to blow their heads off with a shotgun, so there would be no wait but a big mess.

Most of my patients had fixed ideas about their suicide that was mirrored in their births, and they never considered alternate ways to die because there was no alternative at birth. (This has been studied at length by a team in Sweden, led by one of my students, Dr. Bertil Jacobson, director of medical engineering at the Karolinska Institute, a leading medical university and research center located in Stockholm.) (Jacobson \& Bygdeman, 1998)

Dr. Lee Salk of Cornell University Medical Center undertook a study of adolescents who had attempted suicide. (Salk, Lipsitt, Sturner, Reilly \& Levat, 1985) He found that 60 percent of them had three major risk factors occurring simultaneously around the time of birth: respiratory distress, chronic disease in the pregnant mother, and lack of prenatal care for the first 20 weeks of pregnancy. Incidentally, one of the ways we know about the relationship between imprinted pain and suicide is from brain research where several studies indicate that the suicide victim generally has a higher number of serotonin receptors in the brain, but less serotonin activity in the prefrontal cortex where key defensive maneuvers are located. This means less ability to suppress. An extraordinary amount of these receptors were discovered in the blood of those who had recently made suicide attempts; underscoring how the system automatically goes into inhibition in the face of pain. Instead of measuring pain, we measure the repressive forces it provokes. Our study of imipramine binding of blood platelets seem to mirror brain serotonin levels. Interestingly, the greatest risk of suicide is when serotonin levels are at a low ebb; when repression is at its weakest and when the feeling looms near the surface. That is why the depressive has a constant feeling of impending doom and thoughts of killing herself. So long as the gates hold there will unlikely be suicidal thoughts. There is danger when the gates weaken. Because what rises and obtrudes are those very same hopeless feelings hidden in the imprint.

The run-off of the birth sequence remains true to itself and usually does not deviate. When a present-day event is strong enough - such as the death of a spouse or loss of a business - it may trigger off the birth sequence, and then the action of the person is predictable. One might wonder how it is that the loss of a business, no matter how grave, could lead someone to try suicide. It is because the early trauma has infiltrated the adult's behavior so that he cannot distinguish between past and present. The person tries everything to keep the business going, even though logically it should have closed down long ago. Finally, it becomes a hopeless situation and great despair is felt. One of my patients continued pursuing a lawsuit although he was advised that loss was inevitable. He fought and fought and then lost everything, all the while accumulating debt for more lawyers' fees than he could ever hope to pay, which provoked a deep depression. He had many sympathetic features - not recognizing defeat or obstacles when they were apparent - until he could no longer run from the truth. The original truth he ran from was death, which lurked just behind his continued struggles. 
When confronted in adult life with no more options, when one has lost one's means of livelihood, a spouse or child, or when one's friends have turned away, one will tend to follow the prototype to its logical conclusion. When there is no one to help and give support, no one to understand and be encouraging, death seems the only way out. The great problem is that the person never knows where the agony comes from. "It is just such a comfort to know that I can end the pain whenever I want to," remarked one of my patients who was obsessed with death. She did not conceive of and could not adopt new approaches, such as moving to a new city, finding another mate or job, because the imprinted lack of alternatives confines one's vision and imagination within its boundaries.

There are levels of futility that build with each trauma when we are young. Losing a mate at the age of 30 is simply the last straw if we suffered a similar trauma - the loss of a parent as a young child. The force of this accumulated primal pain can reverse the most basic tendency of life - survival - and make anti-survival (suicide) seem logical. The survival instinct can only be defeated when one's psyche is so damaged that the instinct for life reverses itself, and death becomes the goal. Suicide is the option of an organism that has been defeated by life, by experience. It is the logical act of an unloved (ruined) organism, of a childhood so bereft of warmth, caring, kindness and, most of all, hope, as to be nonrecoverable. It is saying: "Nothing that I can do now will work. Nothing will take me out of pain. Nothing will make me feel loved and wanted. There is nothing more to do, no more actouts, no more hope." Then there is suicide, the ultimate act of self-destruction - destruction of the self that hurts.

So long as there is a flicker of hope, death can be avoided. But if the ex-spouse files for divorce and plans to marry someone else, the last vestige of hope is gone. It is shattering when a mother leaves home and deposits her child in the hands of a tyrannical, drunken father or an unfeeling stone of a man who has no emotional reactions to anything. If that child grows up and is again abandoned by his wife who runs off with someone else, the combined pain will be overwhelming, making the agony fatal. For the child there is no logic to it. He can't imagine life going on because, in his feelings, he is still the wretched young boy all alone, helpless, alienated -- hopeless. We can, as therapists, give hope to the adult, but the little boy inside the man is still there, hurting.

Even a glimmer of hope can make the difference between life and death. Look at movie stars such as Marilyn Monroe who seem to have had everything, including adoring fans, and still felt completely unloved and miserable. They don't need more love; after all, the love of a million people isn't lacking. Although this may seem counter-intuitive, what they need is to feel unloved...by the people who counted in their lives - their parents. This is key, because reexperiencing that feeling unblocks the system and is liberating. If we bring the mother of a suicidal patient into a session and she hugs and kisses him all the way through, it will make no difference. But if he lets himself feel completely unloved by her it will make a great difference. Feeling unloved unlocks the defenses that can let love in. And the result of this reliving is a lowering of cortisol levels and a normalizing of vital signs.

People who attempt suicide just don't know what to do anymore to live. They want to end the suffering; but since it is the self who is suffering, the choice is to end life. If they could be promised an end to the suffering, they would not want to die. What hurts is not feeling. The hurt is the clash between upcoming pain and the defenses pushing it down. Once into a feeling there is no more hurt; it is now a feeling.

In order for the person to continue to believe that there is a reason to stay alive, to not revert back to suicidal thoughts and planning, she must eventually feel, in a proper therapeutic setting, the original feelings which underlie her hopelessness. The patient must separate current feelings of loss and sadness from old feelings of despair. Giving hope alone without the patient feeling the hopelessness is not curative. It's only superficially helpful. But in the experience of hopelessness lies the ability of the person to end depression and suicidal tendencies. "Well," one might say, "I've been feeling completely hopeless about losing my girlfriend. That should be enough." Not so; the hopelessness must be felt in its original 
context, otherwise it is not curative. It is only palliative. It is the original feeling that is stored away and must be brought to consciousness so that it won't be triggered off anymore.

Hope lies in the original hopelessness - felt in a safe, warm atmosphere. After a person has felt the complete hopelessness from early on, it becomes automatically transmuted into hope. No one needs to offer any more hope to her. The person is on the road to health where it is less difficult to live than to kill oneself. The hope she now has is reality, not some fantasy.

\section{TREATING DEPRESSION: MEDICATION VS. PSYCHOTHERAPY}

The biggest argument about depression nowadays is how to subdue it and bring it under control. The opposing camps are the medication supporters versus conventional psychotherapy. The latter includes old-fashioned "talk therapies" like psychoanalysis, in which the patient "free associates," seeking to understand what in his past has caused the depression. But dominating the field are the cognitive-behavioral therapies, which focus on the present by attempting to help the patient change his thought and behavior patterns. It seems for the moment, however, that the group in favor of medication has won. Today, psychiatry has become an unwitting arm of the drug companies. Millions of Americans are on selective serotonin reuptake inhibitors (SSRI's), like Prozac, Zoloft, and Paxil, the current gold standard in depression treatment, or a tricyclic antidepressant such as imipramine.

A psychologist investigating depression and its treatment, Ellen Frank, of the Pittsburgh School of Medicine, concludes that antidepressants are most effective when the dosage is sustained over time. "The dose of antidepressant that gets you well, keeps you well," she told Science News in an article about the clash between proponents of psychotherapy versus drugs in the treatment of depression. (Bower, 1991) In the study, first published in the Archives of General Psychiatry, Frank and her colleagues tracked the treatment of 230 people who had experienced recurring periods of major depression for an average of 12.5 years. (Frank, et al., 1990) Of the 53 subjects who received and stayed on a full daily dose of imipramine, 41 remained free of depression for the entire three years. This study also found that psychotherapy plus drugs had no real advantage over the drugs alone -- not particularly convincing testimony to the efficacy of psychotherapy.

Similar results have been found with use of the SSRIs, drugs that are often prescribed indefinitely. Paradoxically, when one is given antidepressants, one may become suicidal; not because of the drugs but because the medication allows for more access to unconscious pain. The drugs, which are supposed to help in repression, actually lift the burden of total repression from the system, which has had to do it all on its own, so that feelings are now coming up. Tranquilizers, on the other hand, may dampen the imprint enough so that the pain does not intrude. The more pain, the greater the dose required. I have seen patients who attempted suicide by ingesting doses that would have been lethal for almost any human being, but who were only put to sleep for 12 hours. They had such massive amounts of pain activating the brain that the medication could not induce death. And deep depressives who had such high underlying activation that ordinary sleeping pills were ineffective.

Since the symptoms of anxiety and depression seem so different, one is tempted to label them as two different diseases. But the fact that repressive drugs can help with both depression and anxiety shows that they are simply different ways the body has of handling the same kind of pain. Drugs may help with both but for different reasons. In anxiety, they serve to plug the holes in the repressive system since the pain is leaking into consciousawareness. In the depressive, as I noted, they function it is to take over some of the job of repression, so that the body is not so burdened. The body feels better because it doesn't have to do everything by itself.

Depression and anxiety are not necessarily separate "diseases"; they are reactions at different stages of neurologic evolution, both involving pain and fear and a stressed nervous system. Anxiety comes first where there is pure unadulterated terror with no possibility of 
defense; and depression second when repression is possible. If we examine animals it seems that they are anxious until placed into a situation with no behavioral opportunities, then they show symptoms of depression. Rats were kept on a slippery slope over a moat of water. When they were exhausted they would fall into the water. After a short time they could not move, were not curious or adventurous - they gave up and seemed depressed.

A depressed person who is not in therapy needs tranquilizers for the same reason that our patients might need them as they approach strong feelings: Repression is weak, so chemical help is needed to bolster it. The drugs help normalize our inner pain-killing pharmacy. We don't want patients with weak defenses to have a free-fall down into remote and highvalence, first-line pain. Medication allows for a slow, methodical descent; it keeps the patient in the primal zone. When patients relive enough of their painful history, they no longer need alcohol, drugs, cigarettes, or painkillers. Less pain, less pain-killers. The difference is that in conventional therapy medication becomes the end-game, the sole ploy. In our therapy, medication is used to achieve our goal, not instead of it.

When it comes to exploring the subconscious roots of depression in most modalities today, the mantra seems to be: Don't go there. There is still the idea that dealing with the deep unconscious is dangerous; and it certainly is, when done without proper knowledge. Within the cognitive school of psychotherapy it is believed that the depressive is locked into "self-defeating" thoughts. Thus, the patient must identify which of these thought patterns are "distorted" and, after that, by way of reason and logic, come up with another way of thinking, one which is "rational" and self-affirming rather than self-defeating. This kind of solution, or attempt at solution, is next to antidepressants on the front line of treatment today. It usually comes from those who assert that we can think our way out of problems; that is, we can literally think our way to health. This is part of the new "reframing" school where we turn something bad into something neutral and inoffensive. We reframe the situation so it won't hurt; there is no notion of deep brain processes, nor of historical imprinted events. Another name for it is pure solipsism. To such therapists, pain is simply all in your mind.

The depressive often tells the conventional therapist, "I just can't make it. I'm stuck." And the therapist is warm and encouraging and insists, "Yes you can." The therapist is unwittingly putting a gloss on the patient's real feeling, which is the imprint. The imprint, which expresses itself as a feeling of "I'm stuck, I can't make it," is primary because the person is unable to change that imprint. Certainly not by talking to a therapist. It is not something thought-out. It is implicit in the birth experience. Optimism or Positive Behavior therapy ignores real feelings which must be dealt with. There is simply no recognition of imprinted memory, even though the process of methylation should inform us otherwise.

There are no such things as self-defeating thoughts, only self-defeating feelings: "I'm no good. I can't do anything." These are not just thoughts suspended in air that one must take back and exchange for new thoughts. They are anchored to physiochemical realities inside that must be addressed. They are evolved not just concocted. Do we actually think that the person makes up these thoughts out of whole cloth? Or do they reflect his life? Further, what and where is this "self" that one is defeating? And what self is doing the defeating? Are there, therefore, two selves?

The real self is the one who has undergone the terrible traumas and is suffering and feeling hopeless and unloved because of real-life early experience. It sends messages up to the thinking centers, which come up with the idea that one is unloved, even while there is a wife and children who are totally devoted to the victim. And a cognitive therapist is quick to point out all this: "After all, you are loved so why do you feel so unloved? You have to change your negative thoughts."

If we ignore the exigencies of critical periods in the brain's development during which its key systems require that certain needs - such as the need for touch - must be met, then we'll never understand why present-day encouragement doesn't work, even if it comes from a kindly and well-meaning psychotherapist. The depressive's "negative" and "self-defeating" thought patterns emanate directly from deep lying imprints and are in accord with the 
body's internal, physiochemical reality. It is the deep-lying imprint wending its way to the top level that results in those defeatist ideas. Thus, the neo-cortex translates the feeling into the specialty of the cortical level - ideas. That cortex does not know that it is responding to something that lies in the depths of the mind. It thinks it is reacting independently. But its free-will has been robbed for a time by exigencies of the imprint. The problem is that the ideas are not in accord with current outside reality. The internal reality always takes precedence over the external one, and the so-called "distorted" thoughts - the ones that cognitive therapists say you have to struggle against - are only symbols for the underlying pain. The evolutionary extensions of the imprint have priority in the psychic economy. We do react to reality but which reality? If we have no notion of an internal one that takes precedence because it has to do with survival, then we must go astray.

That internal reality can represent decades of experience, reinforcing the same few prototypical feelings: "No one wants me. I'm in the way. They hate me." It is true that one can activate and motivate the depressive, encourage him and point to alternatives, and that strategy may help. But all of that is still just fighting against the prototype, which is much stronger and more powerful than words. Ultimately, the prototype will prevail. By and by, the person will fall back into depression. Trying to conquer the prototype means, in effect, conquering your own physiology - a vain task. So long as the imprint is left intact there can be no long-lasting therapy of depression. Without a theory of brain levels we are forced to remain on the last evolutionary level, talking the disease to death.

The notion of depression when unhinged from neurobiology becomes ephemeral and vague and lends itself solely to behavioral explanations. Once we understand that there are generating causes, deep imprints, in producing depression, we understand that cognitive procedures cannot be effective. Deep depression is by definition immune to talk therapy because the "disease" is non-verbal, involves deep-in-the-brain repression, which can't be reached by new ways of thinking. Ideas and insight work on the upper front, left side of the brain - the cognitive part of the brain - while many of the actual feelings are registered and coded deep on the right side of the brain, leaving the traumatic imprint untouched below the repressive barriers. And that is why insight and talk therapy never reaches the basis of one's depression. Medication, on the other hand, calms the pain bio-chemically. Both approaches disconnect thought from feeling. It also suppresses the one thing that can make us well -- our history.

Whether they are in favor of treating depression with medication or psychotherapy or a combination of both, most psychotherapists in the field adhere to the notion that suppressing depression is the same as curing it. It is certainly possible to suppress symptoms, to give the patient relief, and help him function better and enjoy life more. But the underlying problem remains, as reflected by the fact that the symptoms usually return when treatment ceases, and many chronic depressives elect to stay on the medication permanently in order to suppress their symptoms indefinitely. So long as we leave the imprint intact in dealing with the depressive there will be no cure and a vulnerability to more disease.

The dilemma in psychiatry and psychotherapy today is the focus on the level of presenting symptoms. This makes drugs necessary and makes treatment palliative and noncurative. The idea of repressing symptoms with drugs may work, but it ultimately goes astray because the symptoms are just that: symptoms of an underlying, unconscious pain. Without probing into history, all one can do is treat appearances (phenotypes) instead of causes (genotypes).

There are many new drugs on the market that are heralded as a "breakthrough." I will discuss one recent one that makes that claim, and that is Ketamine. It is something that was used as a light anesthetic fifty years ago, and was called "twilight sleep." But it is claimed to be effective in the treatment of depression. The question is why?

Ketamine was originally aimed at horses in veterinary medicine, then transferred to humans. It is not yet legal as a treatment for depression. In experimental studies it is reported as quite effective. It was first tried by scientists at the National Institute of Mental Health. 
Thoughts of suicide diminished and depression eased for a time, though not over a long time period. So what happens once this drug is infused into the patient's system? There is a feeling of dissociation and feeling drugged. Thoughts of suicide diminished and depression eased for a time, though not over the long term. So what happens once this drug is infused into the patient's system? There is a feeling of dissociation and feeling drugged. What Ketamine does is fill up the space between neurons with the neurotransmitter glutamate, producing a flood of the drug in the prefrontal cortex. And that helps activate mental activity, making the person better able to handle feelings. Their conclusion was that depression is caused by an imbalance in the regulating action of glutamate. Ketamine does activate parts of the limbic system, including the anterior cingulate cortex. In this sense it is an "upper," gathering up energy and activating the system against its basic repression/deadness, thus lifting depression. Remember, that anything that eases repression will help depression. Generally, then, any medication to combat depression must energize against repression. In short we need to soften the massive repression involved in depression if we are to help patients. Thus the biochemical GABA - gamma amino butyric acid, which works to inhibit the transmission of nerve impulses - is partially undone with ketamine, thus lessening some of the repressive work accomplished with GABA (Diazgranados et al., 2010; Vutskits et al., 2007).

The researchers believe that it is that imbalance that is responsible for depression. I believe we need to ask, what caused that imbalance in the first place? Since its effects are ephemeral I believe we need to first discover how to right the balance that endures. It seems to me that it might well be the early traumas that disrupt so much neurochemical balance in the brain. Depressives may be low on glutamate because excessive activity became dangerous; that is, during the trauma at birth shutting down was survival.

Every breakthrough has one key effect: easing repression and lifting its gates. Since I posit that depression is repression elevated to a higher level, it would make sense that easing repression would make a permanent difference. Otherwise we are obliged to work around the edges, tweaking symptoms and never reaching causes.

Symptoms are signs of something wrong; we don't want to drive the warning signal away. We want to heed its message. In conventional therapy we have extracted the symptom out of the person for treatment, instead of seeing how the symptom emanates out of a biologic history. We make the symptom well, not the person.

There is an interview in the British scientific journal, New Scientist with psychologist Joe Griffin, the co-creator of the therapeutic approach known as Human Givens, which has gained some acceptance in Great Britain. (Kiser, 2003) He states: "Research shows that any therapy or counseling that encourages people to introspect about their past will inevitably deepen depression." With this advice, all one can do is focus on the here-and-now and never get better. It is the essence of historical solipsism. There is no past, nothing affecting us in our history. It is a turn on the Freudian notion of the dangers lurking when we meddle with the unconscious. When we ignore or don't understand history we are confined to an ahistorical therapy. This can lead to a futility on the part of the doctor and patient; sitting by helplessly, infusing drug after drug into the patient to control her symptoms, or discussing them endlessly, in vain.

In order for psychotherapy to be effective, we need to take the heart of the feeling-"I can't make it" - and trace it back to its origins in the brainstem, which is what Primal Therapy does. If we simply try and convince the patient through a talk-therapy session that yes, he/she can make it, we are widening the gap between his/her waking, thinking mind and his/her feelings. The feelings are real and are part of neurophysiology. In our therapy we take the phrase, "can't make it," and use it to allow the patient to feel it further; once locked into the feeling it will take him/her down the chain of pain in ordered fashion. In psychotherapy we have to be careful not to be a cheerleader for the patient and simply try and make her feel better through verbal comfort and consolation. He/She appreciates our encouragement, thrives on it, comes back for more, and each day therefore becomes more distant from herself. It will not make his/her better. And what is "better?" Being 
him/herself, being in alignment with feelings, there is nothing better than that. Our verbal encouragement makes him/her not herself, however, and if we rely on kinds words only, he/she will not be in accord with how he/she really feels. If the reality of inner feelings is, "I feel unloved," then encouragement by a kindly therapist defies reality.

As psychotherapists, we want to be a good parent for the patient as much as he/she wants us to be. We know that parents should encourage and support their children. But feelings are engraved in the patient's system, after that it is too late to make any easy changes through the use of kind words and verbal encouragement. The window of opportunity has passed. We cannot love neurosis away.

\section{ON RELIVING: DEFEATING THE FEELING OF DEFEAT}

There is scarcely a professional among us who believes in the absolute necessity of reliving old events and altering their imprints; yet it is that very process that is curative. It is curative because it deals uniquely with history and memory. This is not to be confused with recall. Recall is cerebral, neo-cortical. Reliving the imprint is neuro-physiologic, and is remembered in that way. While imprints are usually not in the therapist's lexicon, I believe it will be the sine qua non for the future of psychotherapy.

There are now hundreds of studies in the scientific literature documenting the effects of pre-birth and birth traumas on later symptoms and behavior (and this is discussed in detail in Primal Healing.) There are research case studi es we did to verify my point. I have written about the UCLA experiment in my book (Janov, 1996) but I want to sum up the importance of it. This is research we did together with Dr. Donald Tashkin, former director of the Pulmonary Laboratory in 1992. Two patients were wired to many instruments while we helped them into a reliving session, a primal. Neither patient observed the other so we had a rather pure experience on the part of both men. They both relived severe oxygen deprivation during a birth trauma, something we had not planned at all. After being immersed in a memory of oxygen deprivation they began what I term "locomotive breathing," because that is what it sounds like and seems to emanate in part from the brainstem, in particular the medulla. This deep, raspy, rapid, compulsive breathing went on for over twenty minutes.

The heavy breathing was an attempt to compensate for the lack of oxygen they experienced during the memory event. This is never a voluntary effort. It seems "forced" on the person from low in the brain. It is as though the patient is making up for the deprivation event by gasping for air. Once begun it is very hard to stop until it has run its course.

Heavy breathing can go on for many minutes and it may take many sessions for the cause to be comprehensible. Though this heavy breathing goes on for up to twenty minutes there never is any hyperventilation. After the reliving, we did another experiment where each patient mimicked the primal in every way (same movements and heavy breathing) except for not being in the past. That is, it happens out of a deliberate action by the patient living in the present. Both got dizzy and almost fainted after 3 or 4 minutes in what was clearly a hyperventilation syndrome (clawed hands).

It happens systematically to those who attempt to go back to the past without being totally in the memory. In fact it is one of our controls on the veracity of the feeling. If they run out of air right away it is simple abreaction, and unconnected and not integrated event. The reason is rather simple; the subjects were breathing voluntarily, not automatically out of the memory. They were breathing from "on top," not from the bottom. The memory offers us the truth of the experience.

What the researchers from the pulmonary laboratory found was that when the patient was back in the old feeling and its context of anoxia at birth the body needed oxygen; the patient was "back there" in every way, not the least of which was physiologically. They go back in a complete biologic state. What we found at UCLA was that despite the heavy prolonged breathing the acid-alkaline balance did not change. The conclusion of the UCLA 
investigators, who were not associated with Primal Therapy in any way, was that no other factor other than memory could account for the results. In short, the life-and-death memory was real. It was imprinted. Despite the fact that the oxygen was normal in the room the brain was sending signals of a great lack of oxygen, and the heavy breathing ensued. There was no hyperventilation syndrome because the whole system was back in history re-experiencing a key trauma and urgent need of oxygen. They were reliving not just in their heads or their thoughts but with every part of them. Patients are indeed in their past. They are living in their history, living in their personal past; and, I might add, living inside a brain from antiquity. Their lives are revolving around history with only a dim awareness of the present when they are reliving in a primal.

These experiments are the best supporting information for primal therapy, as the experience cannot be faked. The fact that his imprint endures and is immutable means that it constantly affects so much of our feelings, moods and behavior. It means that there is a profound origin for depression which began its life before we began life on the planet. In the case of one of our patients trying to get born against massive anesthetic the feeling was, "I just can't try any more. I have to give up. It is hopeless." Here was the deep preverbal forerunner for depression; the physiology of depression.

Once we establish that we are propelled by imprints embedded in an ancient brain we see that it has everything to do with our current behavior and symptoms, then we must acknowledge that the primitive brain affects not only our breathing but also most of our current life, our moods, values and attitudes. Those imprints must be considered when we want to understand depression. It is not just breathing that is affected but most of the brainstem functions; digestion, elimination and many mid-line events. We go to doctor after doctor to try to solve a stomach problem when the memory will give it all up as soon as we can access it. It will tell us all because it was there at the scene "of the crime." It will tell us of the carrying mother's anguish, her use of drugs and alcohol or her own depression. Therein lies the answer - history. It divulges all of its secrets when we descend to meet it. It won't come up to confess its history verbally; we need to meet it half way. Then it may say in its own nonverbal way, my stomach aches, as we plunge into history; my stomach is not working well. Later on there is colic that speaks more of what is wrong. And still later a drug addiction. The point is that when life is not going well and one is unhappy for unknown reasons we need to look at generating sources. It is never a matter of thinking healthy thoughts; it is a matter of knowing what underlies unhealthy thoughts.

This is significant because it can open up a universe to us about the depths of man's unconscious. It confirms that very early experience is impressed into us, not just as a memory but as a wound that needs healing. The corollary to this is that the early need for love endures, and does not change throughout our lifetime. We seek symbolic, substitute fulfillment but it is never fulfilling and compels us to go on seeking more and more, always in vain, because it is symbolic. The critical time when need must be fulfilled has passed. And we have found that we can only heal where we are wounded. This means a return to relive events deep imprints where breathing is organized. Thus, if the "wound" / trauma affected breathing at birth, due to a heavy dose of anesthesia, then it must be revisited and relived; a return to generating sources. This usually normalizes many functions, from cortisol levels to natural killer cells as well as blood pressure and body temperature. With reliving the system is allowed to function normally.

The marks that originally appeared during the birth trauma may again appear in a later session. (We have photographed these marks; they can be found in my books). The baby-cries during a session can never be repeated by the patient after it. It is clearly not a simulation. In other words, the past and its neurobiology remains encapsulated inside of us. This may account for a number of lingering diseases in adult life. What is remarkable is that it is impervious to later experience; no matter how much approval an actor gets he always needs more. It is why I maintain that only re-experiencing in the context of an old traumatic memory can be curative. Consider, in the session, despite the adequate oxygen in the room 
the brain is signaling a serious lack of it and the body responds accordingly-- gasping for air, living for the moment in the past. Engulfed by memory.

One would think that we learn from experience but those with heavy pain keep having the same experience over and over. That is why those who have one auto accident are likely to have another.

We have to ask the question, what is about reliving that is so important? Why is consciousness so critical? It means acknowledging the evolution of the brain. Although that seems evident, many current therapies treat the patient ahistorically, as if he/she had no history and there was no personal evolution. It is creationism in the guise of science. The universe was not created magically in seven days, and mental illness does not suddenly appear in people one day, without regard to their individual evolution. History must be the primary goal in psychotherapy if we want to get better. After all, what does it mean to "get better?" I believe it means getting our selves back, the self that hurts and feels. We must get our feelings back to become fully human.

Why relive? Because without access the agony portion of the memory has never been completely experienced. We carry that painful residue continuously inside of us. In Primal Therapy, we now react fully to the prototype. We no longer hold pain in storage where it has done its damage.

Depression is a terrible state. It feels devastating and never-ending, but fortunately, it no longer has to be. There is a way out; and that way out is the way in. But we have to have a map of the way; otherwise we are lost. The reason so many therapists believe it is untreatable except by drugs is that heretofore they have had no way to probe the inner depths of their patients. And that is where the problem lies. Depression seems like it is in the present, but actually, the person is walking around engulfed and ruminating in his/her past. In Primal Therapy, we help put the past back into history and thus bring the person into the present, now unencumbered. We cannot leave our past behind by any great amount of will or effort. In fact, trying to do so with will power only insures failure. We need to let go of that strong will and submerge ourselves into our feelings. In therapy, we provide access to ourselves, no more no less. But that is a lot, for it means an end to depression.

I use the terms radical and revolutionary for my therapy with caution; yet I believe it is. It is revolutionary, in form and content. Primal Therapy is a radical departure from the face-aface, insight-besotted discussion between two unequal partners; one with a worldly knowledge and an unerring moral stance, the other a willing neophyte genuflecting psychologically to learn what the worldly one dispenses, acquiescing to the outside instead of the inside. I speak from experience, having practiced insight therapy for many years. The majesty of it all is intoxicating for the therapist. The power of directing someone else's life is seductive - and wrong!

Sadly, in the name of progress and being modern we have moved away from the past into a more present approach. There is an apotheosis of the present, of the here-and-now, and a move away from the one thing that is curative--history. More sadly, for one hundred years we have been talking to the wrong brain! It is that brain - the intellectual, unfeeling brain that prevents any hope of a cure for emotional illness. Talking to the brain that talks was fine a century ago but now we know so much more about the brain and what it contains; we can speak to the brain that feels in its own language.

We need to learn a new language - that of the unconscious - a language without words that could help us make profound change in patients. After all, we call it "mental illness." Yet, words often are the defense against feeling. Our goal is to produce feeling human beings, not mental giants. When one feels the prototypic trauma, one is on one's way to a solution for depression. That, plus feeling all of the harshness, the excessive discipline, the indifference and the lack of caring in one's family; and expressing all of the feelings and needs held back for those years. Expressing all that with the original feelings involved - that is why it is so forceful and terribly sad. The crucial, curative difference is that our therapy is not about the adult shedding a few tears - the adult crying about the past - but it is about becoming the 
baby and child with wrenching sobs and agonizing screams. "Be nice to me! Hold me! Cherish me. I'm your son! Let me be me. I'm your flesh and blood. Show that you want me. Let me express how I feel!" Those are the needs. When all that is physiologically reexperienced as what occurs during a Primal re-living, depression is no longer a mystery. And only when it is all felt, over months of reliving plus the birth trauma when appropriate, will the depression be resolved permanently. So the more one feels what caused the closure of the system, the more it becomes safe for the system to become open.

Finally, love can get in.

\section{REFERENCES}

Anand, K. J. S., \& Scalzo F.M. (2000) Can adverse neonatal experiences alter brain development and subsequent behavior? Biology of Neonate, 77(2), 69-82.

Belluck, P., \& Carey B. (2013, May 6) Psychiatry's guide is out of touch with science, experts say. New York Times. Retrieved June 21, 2013, from The New York Times website: http://www.nytimes.com/2013/05/07/health/psychiatrys-new-guide-falls-short-expertssay.html?pagewanted=all\&_r=0

Blackburn E.H. \& Epel E.S. (2012) Telomeres and adversity: Too toxic to ignore. Nature, 490(7419), 16971.

Booij L., Wang D., Lévesque M.L., Tremblay R.E., \& Szyf M. (2013) Looking beyond the DNA sequence: The relevance of DNA methylation processes for the stress-diathesis model of depression. Philophical Transactions of the Royal Society London B Biological Sciences, 368,1615.

Bower, B. A. (1991, Jan. 26) Melancholy Breach: Science and Clinical Tradition Clash amid New Insights into Depression. Science News p. 57. Society for Science \& the Public, Washington D.C.

Diazgranados, N., Ibrahim, L., Brutsche, N. E., Newberg, A., Kronstein, P., Khalife, S., Kammerer WA, Quezado Z, Luckenbaugh DA, Salvadore G, Machado-Vieira R, Manji HK, \& Zarate Jr., C. A. (2010). A randomized add-on trial of an N-methyl-D-aspartate antagonist in treatment-resistant bipolar depression. Archives of General Psychiatry, 67(8), 793-802.

Dokoupil, T. The Suicide Epidemic. (2013, May 22) Newsweek. Retrieved on June 21, 2013 from The Daily Beast (Newsweek) website: http://www.thedailybeast.com/newsweek/2013/05/22/whysuicide-has-become-and-epidemic-and-what-we-can-do-to-help.html

Dolinoy D.C. (2008) The agouti mouse model: an epigenetic biosensor for nutritional and environmental alterations on the fetal epigenome. Nutrition Reviews, 66(Suppl 1), BS7-11.

Doward, J. (2013, May 11) Psychiatrists under fire in mental health battle. The Guardian. Retrieved June 21, 2013, from The Guardian website: http://www.guardian.co.uk/society/2013/may/12/psychiatrists-under-fire-mental-health

Frank E., Kupfer D. J., Perel J. M., Cornes C., Jarrett D. B., Mallinger A.G., et al. (1990) Three-year outcomes for maintenance therapies in recurrent depression. Arch Gen Psychiatry, 47(12): 1093-9.

Freedland K. E. \& Carney R. M. (2013) Depression as a risk factor for adverse outcomes in coronary heart disease. BMC Medicine, 11, 131.

Freud, S. (2005). On Murder, Mourning, and Melancholia. London: Penguin.

Gilson, M. \& Freeman A. (1999). Overcoming Depression: A Cognitive Therapy Approach for Taming the Depression BEAST. Boulder (CO): Graywind Publications.

Gurza, A. (1976). Scientific revolutions and the role of primal theory in psychology. The Journal of Primal Therapy, 3(2), 193-213.

Gurza, A. (2005) Primal Therapy: A revolutionary shift in the paradigm of psychology. In A. Janov. Grand Delusions: Psychotherapies Without Feeling. Santa Monica (CA):The Janov Primal Center. Retrieved June 21, 2013 from the Janov Primal Center website: http:/ / www.primaltherapy.com/GrandDelusions/GD99.htm

Hollenbeck A. R., Grout L. A. , Smith R. F., Scanlon J. W. (1986) Neonates prenatally exposed to anesthetics: four-year follow-up. Child Psychiatry and Human Development, 17(1), 66-70.

Institute for Health Metrics and Evaluation (IHME) (2010) Global Burden of Diseases, Injuries, and Risk Factors Study 2010. (CBD 2010) Retreived in June 21, 2013 from the IHME website: http:/ / www.healthmetricsandevaluation.org/gbd/research/project/global-burden-diseasesinjuries-and-risk-factors-study-2010 
Jacobson B. \& Bygdeman M. (1998) Obstetric care and proneness of offspring to suicide as adults: casecontrol study. British Medical Journal, 317(7169),1346-9.

Janov, A. (1996). Why You Get Sick and How You Get Well: The Healing Power of Feelings. West Hollywood, (CA): Dove.

Janov, A. (2006) Primal Healing: Access to the Incredible Power of Feelings to Improve Your Health. Franklin Lakes, NJ: New Page.

Janov, A. (2011). Life before Birth: The Hidden Script That Rules Our Lives. Chicago: NTI Upstream.

Kiser, B. The Dreamcatcher. (2003) New Scientist, April 12, 2390th ed.: 46.

Laplante, D. P., Barr R.G., Brunet A., Du Fort G. G., Meaney M. L., Saucier J-F., et al. (2004) Stress during pregnancy affects general intellectual and language functioning in human toddlers. Pediatric Research, 56(3), 400-10.

Lipsman N., Woodside D. B., Giacobbe P., Hamani C., Carter J. C., Norwood S. J., et al. (2013) Subcallosal cingulate deep brain stimulation for treatment-refractory anorexia nervosa: a phase 1 pilot trial. Lancet, 381(9875), 1361-70.

MacLean, P.D. (1985). Brain Evolution Relating to Family, Play, and the Separation Call. Archives of General Psychiatry, 42, 405-417,

MacLean, P.D. (1990). The triune brain in evolution: role in paleocerebral functions. New York: Plenum Press.

Mayberg H.S., Lozano A.M., Voon V., McNeely H.E., Seminowicz D., Hamani C., et al. (2005). Deep brain stimulation for treatment-resistant depression. Neuron, 45(5), 651-60.

Mojtabai, R., \& Olfson M. (2011). Proportion of antidepressants prescribed without a psychiatric diagnosis is growing. Health Affairs (Millwood), 30, 1434-442.

Morbidity and Mortality Weekly Report (MMWR), (2013, May 3). Suicide Among Adults Aged 35-64 Years - United States, 1999-2010. Centers for Disease Control and Prevention (CDC) Retrieved on June 21, 2013 from the MMWR website: http://www.cdc.gov/mmwr/preview/mmwrhtml/mm6217a1.htm

Nemeroff, C. B. (1998) The Neurobiology of Depression. Scientific American, 278(6), 42-49.

Nyberg, K., Buka S. L., \& Lipsitt L. P. (2000) Perinatal medication as a potential risk factor for adult drug abuse in a north american cohort. Epidemiology, 11(6), 715-16.

Okereke O.I. Prescott J., Wong J. Y., Han J., Rexrode K. M., De Vivo I. (2012) High phobic anxiety is related to lower leukocyte telomere length in women. PLoS One, 7(7), e40516.

Parker-Pope, T. (2013, May 2) Suicide Rates Rise Sharply in US. New York Times. Retrieved on June 21, 2013 from the New York Times website: http://www.nytimes.com/2013/05/03/health/suiciderate-rises-sharply-in-us.html?_r=0

Salk L., Lipsitt L. P., Sturner W. Q., Reilly B. M. \& Levat R. H. (1985) Relationship of maternal and perinatal conditions to eventual adolescent suicide. Lancet, 1(8429), 624-7.

Schroeder, M., Krebs, M.O., Bleich S., \& Frieling, H. (2010). Epigenetics and depression: Current challenges and new therapeutic options. Current Opinion in Psychiatry, 23(6), 588-92.

ScienceDaily (2013, March 6) "Deep Brain Stimulation Shows Promise for Patients With Chronic, Treatment Resistant Anorexia Nervosa." Retrieved June 21, 2013 from the ScienceDaily website: http:/ / www.sciencedaily.com/releases/2013/03/130306220838.htm

Solomon, A. (2002) The Noonday Demon: An Atlas of Depression. New York (NY): Simon \& Schuster.

Vutskits, L., Gascon, E., Potter, G., Tassonyi, E, \& Kiss, J.Z. (2007). Low concentrations of ketamine initiate dendritic atrophy of differentiated GABAergic neurons in culture. Toxicology, 234, 216-26.

Weaver I.C., Cervoni N., Champagne F. A., D'Alessio A. C., Sharma S., Seckl J. R., et al. (2004). Epigenetic programming by maternal behavior. Nature Neuroscience, 7, 847-854.

Williams, A. (2004, Feb. 2) Vanishing Act. New York Magazine. Retrieved on June 21, 2013 from the New York Magazine website: http:/ /nymag.com/nymetro/news/features/n_9787/

Wolkowitz O. M., Reus V. I., Mellon S. H. (2011) Of sound mind and body: depression, disease, and accelerated aging. Dialogues in Clinical Neurosciences, 13(1). 25-39.

World Health Organization (WHO) (2004). Global Burden of Disease (GBD). Retrieved June 21, 2013 from the WHO website: http:/ / www.who.int/topics/global_burden_of_disease/en/ 